\title{
NASA Robotic Mining Competition
}

\author{
MSOE 2018 NASA Robotic Mining Competition Competition Team \\ Milwaukee School of Engineering
}

\begin{abstract}
The sky's the limit, so the saying goes, yet humankind is trying to make a footprint on our neighbor Mars. Because of Mars's distance from Earth, NASA would like to develop a mechanism to help astronauts to collect water crystals found below the sandy Martian regolith. As a result, they task the Robotic Mining Competition (RMC) teams to design a robot that can steer through a simulated Martian terrain, collect gravel (simulated water crystals) located under the regolith material (BP-1), and bring the gravel back to the collection bin. The RMC teams must work cooperatively in order to design and build such a robot, and to out-compete all their competitors.
\end{abstract}

\section{Overview}

For a week in May, fifty teams from across the United States will be attending the annual NASA Robotic Mining Competition at the Kennedy Space Center in Cape Canaveral, Florida. The NASA Robotic Mining Competition is an event where teams compete with their mining robots on a simulated Martian terrain to attain gravel hidden under approximately $30 \mathrm{~cm}$ of a sandy material called regolith.

\section{Purpose}

The goal for the Milwaukee School of Engineering's newly-formed team, Space Raiders, was to set a new standard for the competition team. In past years, the competition robot was recreated each year by a senior design team. However, each senior design team was new and did not build upon the ideas of previous years' robots. Therefore, the goal for the Space Raiders was to create a competition team to be competition-ready by allowing multidisciplinary team members and inclusivity with all undergraduate and graduate students at the Milwaukee School of Engineering. The senior design team will also create research and development projects which the competition team could utilize in future robots if desired. Future robots will then be able to build upon the design previously made by the competition team instead of a new robot every year. For the competition team's first year as a new team, the team wanted to create a simple robot to successfully compete in the competition and to serve as a basis of design for next year's team. This report will serve to describe the engineering design process used by the competition team to accomplish their goals, as per the systems engineering process described by NASA.

\section{Problem Definition}


The NASA Robotic Mining Competition has strict rules pertaining to the design and construction of the mining robot. This year represents a change in the scoring for all of the mining robots; instead of scoring based on the collection of the regolith, the scoring is based on the collection of the gravel located $30 \mathrm{~cm}$ deep into the regolith. None of the past MSOE teams have succeeded in collecting the gravel. The Caterpillar Mining Arena is 3.78 meters wide and 7.38 meters long with obstacles like craters and boulders to simulate conditions on Mars. The goal of the robot is to navigate the simulated Martian environment, collect gravel at the end of the arena, and transport at least $1 \mathrm{~kg}$ of gravel back to a collection bin within 10 minutes. Successful communication will be vital for the mining robot for manual control of the robot. Although autonomy is encouraged by the NASA RMC rules, it has not been successfully implemented on this year's robot. Other considerations based on the weight, dust creation, energy consumption, and max dimensions have been accounted for the mining robot.

\section{Deliverables}

The goal for the Milwaukee School of Engineering's Space Raiders was to deliver the following:

- A functional mining robot adhering to the rules set forth by the NASA RMC

- Systems Engineering Report

- Outreach Report

- Team Presentation

\section{Stakeholders}

The stakeholders for the Space Raiders team were the following:

- Brady Corporation

- Igus Incorporated

- Marlin Technologies

- Milwaukee School of Engineering

- National Aeronautics and Space Administration

- Space Raiders Team Members

- West Bend Optical

- Wisconsin Space Grant Consortium

\section{Systems Engineering}

The intention of the Systems Engineering Report from the Milwaukee School of Engineering was to document what this team has accomplished on their mining robot over the past year for the NASA RMC competition. The guidelines the team followed was derived from the NASA Systems Engineering Handbook. The previous year's systems engineering phase cycle was used 
as a reference to achieve a successful and efficient robot design. Each phase of the robot was divided into four phases that demonstrate the completion of the robot.

\section{Phase A: Concept Development}

\section{Design Philosophy}

The Milwaukee School of Engineering's NASA RMC team's decisions were made using a design matrix and input from each team member. For the beginning decisions, such as what the digging system would be, the team made sure to include inputs from all sub-teams. However, with smaller decisions, such as which cameras would be used, the individual sub-team impacted by the decision had control, with inputs and restrictions from the other sub-teams. For all major decisions, members gave reports and received feedback Dr. Farrow, the team advisor. Dr. Farrow also helped the leadership board to plan outreach and social events for the team.

\section{Systems Requirement}

\section{NASA}

NASA provided a list of guidelines, which were essential to follow in order for the team to compete. This list included restrictions of the robot, banned materials, the layout of the the Caterpillar Mining Arena, instructions on robot to control room communications, and a breakdown on the process of scoring in the upcoming competition. These guidelines were reviewed carefully before the decision-making process began and were cross-checked to ensure that they were followed.

\section{Team Self Imposed Requirements}

The main goal of the MSOE NASA RMC team was to develop a robot for the new rule of collecting gravel that represents simulated Martian icy regolith. The robot must operate by collecting the gravel, transporting the gravel, and dropping off the gravel at the collection bin. The robot must not surpass the allowable current to blow fuses and kill the robot. The cost of the robot must not exceed the budget and must pass NASA's inspections in dimensions, bandwidth, and weight to pass.

\section{Chassis and Drivetrain Sub-System}

The main goal of the Chassis and Drivetrain sub-system was to develop a structure for the robot that was capable of supporting the Material Handling digging mechanism and can drive the entire weight of the robot. 


\section{Material Handling Sub-System}

The main objective of the Material Handling sub-system was to design, analyze, and build a lightweight digging system and collection system. The requirement was that the robot had to collect at least $1 \mathrm{~kg}$ of gravel within 10 minutes. Another requirement was that all the electrical components had to be under 12 volts for the motors and actuators.

\section{Controls Sub-System}

The main objective of the Controls sub-system was to design a modular and expandable control system for the robot. The system had to be easily expanded to allow for additional motors and sensors as well as an automation sub-system, which is planned for next year. The current requirement is full manual control. NASA required that the robot has an average data utilization of less than $2,500 \mathrm{~kb} / \mathrm{s}$ across a match. Another requirement was that the robot would use less than 200 watts over the course of a match.

\section{Phase B: Preliminary Design}

The team used a simple three step process to decide on the preliminary design. The first step was brainstorming as a group. In a single session, the students came up with as many ideas for different aspects of the robot. Next, each student was assigned at least two of these aspects to research. If they found another aspect, they would add it to the list of aspects. That person could either research this new aspect or they could pass it to another student. Once all the aspects were researched, they were compared. The last step in the preliminary design process was to compare the different aspects.

The first comparison was between the aspects and the competition constraints. If an aspect did not fit in the constraints of the competition, or the team decided it was not feasible to build, it was removed.

\section{Digging}

The next comparison was between digging methods. As the focus of this year's team was to dig deep enough to reach the gravel, the digging method was given primacy. The criteria used for comparison of these methods were:

- How much dust it would create

- How deep could it get

- How easily it could be made

- How much would it weigh

- How easily could it handle the regolith

- How fast could it collect material

- How much would it cost to make

- How much time would it cost to build

- Which one would the students like to build the most 
The depth of digging and the weight of the mechanism was weighed twice as much as the other criteria as seen in the table below. The digging methods were ranked 1 to 4 , with 1 being the least desirable. The table below shows the results.

\begin{tabular}{|c|c|c|c|c|c|c|c|c|c|}
\hline & Dust & $\begin{array}{c}\text { Deep } \\
(\mathrm{x} 2)\end{array}$ & Make & $\begin{array}{c}\text { Weight } \\
(\mathrm{x} 2)\end{array}$ & Regolith & Speed & Price & Time & Total \\
\hline $\begin{array}{c}\text { Bucket } \\
\text { Conveyor }\end{array}$ & 2 & 2 & 4 & 4 & 2 & 3 & 2 & 4 & 29 \\
\hline $\begin{array}{c}\text { Digging } \\
\text { Wheel }\end{array}$ & 3 & 1 & 2 & 3 & 3 & 2 & 4 & 1 & 23 \\
\hline $\begin{array}{c}\text { Archimedes' } \\
\text { screw }\end{array}$ & 4 & 3 & 1 & 2 & 1 & 1 & 3 & 2 & 22 \\
\hline Trencher & 1 & 4 & 3 & 2 & 4 & 4 & 1 & 3 & 28 \\
\hline
\end{tabular}

Figure 1: Design matrix for digging method

Of the original 12 options for digging, the trencher method was chosen. Although the bucket conveyor was a point above the trencher, the current team wanted to challenge themselves to create a trencher as opposed to using a bucket conveyor which has been exhausted by previous teams in the year's past. Next the remaining aspects were checked for compatibility with the trencher system. Any aspect that was not compatible with the trencher was removed.

\section{Movement Device}

The next decision was method of movement. For the last two years, the MSOE robot ran on treads. Both years the method of transportation failed. Again, a list of options including treads, screws, and wheels were created and researched. Wheels were decided on because they were less complicated to work with in terms of access, programming, and assembly. The ideas the team wanted were different types of wheels such as tractor wheels, the toy-brand Power Wheels's wheels, beach cart wheels, airless ATV paddle wheels, and hoverboard wheels. Other design features that the team discussed were whether to design the wheels to be metal, designed for traction, concave in, and airless. From these desires, the team closely analyzed the costs and procedures. Metal wheels were being developed in a model, but the team was later advised to purchase hoverboard wheels. The final wheel choice was determined in the final design process with more concern to the frame.

\section{Steering}

Steering was less of a priority in the preliminary design process because the team's primary goal was to power the robot to move and operate the trencher. The steering methods were described and a vote was taken to determine which steering technique the team wanted to utilize. A decision matrix was made to determine which application was suitable. 


\begin{tabular}{|c|c|c|c|c|c|}
\hline & $\begin{array}{c}\text { Steering Ability } \\
(20 \%)\end{array}$ & $\begin{array}{c}\text { Programming } \\
(20 \%)\end{array}$ & $\begin{array}{c}\text { Cost } \\
(30 \%)\end{array}$ & $\begin{array}{c}\text { Assembly } \\
(30 \%)\end{array}$ & Total \\
\hline Tank Drive & 5 & 7 & 7 & 4 & 5.7 \\
\hline Skid Steering & 5 & 9 & 10 & 9 & 8.5 \\
\hline $\begin{array}{c}\text { Rack and } \\
\text { Pinion }\end{array}$ & 9 & 7 & 4 & 4 & 5.6 \\
\hline
\end{tabular}

Scale: 1 (Poor) - 10 (Excellent)

Figure 2: Decision matrix for steering method

When evaluating the decision, it was clear from the decision matrix that it favored skid steering. Skid steering allowed the team less complexity in the drivetrain and gave Controls less programming to focus on. The skid steering also reduced weight and kept the center of gravity closer to the center. Due to choosing the skid steering method, the team chose to go with four wheels in the design.

\section{Control System}

The main priority for the control system was that it be easily expandable. Future robots are planned to use variants on this year's control system. Because of this, the system had to be designed with the possibility of future automation in place. For this reason, the team decided to make use of two Xbox Kinects, a Beaglebone Black, a Raspberry Pi, and an Arduino. One would be mounted on the front of the robot and the other would be mounted on the rear. This design was chosen because the Xbox Kinects have the ability to produce depth maps which will be useful for adding automation in the future. The decision to have two was made in order to allow the robot to be able to navigate autonomously in the future when travelling both forwards and backwards. The decision to use both a Beaglebone Black and a Raspberry Pi on the robot was made because the Beaglebone black supports a real-time processor and can interface with lowlevel I/O directly and the Raspberry Pi has enough USB ports to support multiple cameras. The decision to use an Arduino was made due to the ease with which one can be programmed.

\section{Phase C: Final Design}

\section{Chassis and Drivetrain}

The Chassis and Drivetrain sub-team worked together to design a chassis that would be lightweight, but also able to handle the stress and strain created by the trencher while collecting material. Due to the complexity of building the Material Handling sub-team's trencher, the 
chassis and drivetrain sub-team focused on making a stable, but simple design to enclose the Material Handling and Controls sub-systems.

\section{Chassis}

The main building material chosen for the chassis was 2 inches by 1 inch 6063-T5 aluminum rectangular tubing. The rectangular tubing was chosen due to aluminum's lower density and its ability to enclose wires and other electrical components. The "box-like" chassis was a simple design which was determined to be easily weldable by the newly-formed competition team. Although aluminum has a history of being difficult to weld, senior students at the Milwaukee School of Engineering were able to lend their help and expertise to help weld the new chassis. Other considerations taken into account would be that the yield strength of the aluminum alloy 6063-T5 after welding becomes 6063-O. 6063-O is the softest state of 6063 which lowers its yield strength of 21,000 psi to 7000 psi according to MatWeb.

Another consideration for the chassis was the need for the trencher to have a great force to push down on its boom. The trencher needed to have a large amount of force to drive the boom through the ground. Therefore, four diagonal supports were added on the sides of the chassis and where the actuators were located to distribute the forces the actuators would be producing on the upper frame of the chassis. The trencher also needed considerable supports due to the need for an opening for the boom of the trencher to cut through the ground. The need for the trencher to have a huge amount of space left little to support the weakened structure around the trencher in the front of the robot. Therefore, the trencher needed to have at least a support bar towards the back of the robot. Overall, the weight of the chassis was centered as close to the ground and in the middle as much as possible to prevent tipping when the robot was digging.

For the chassis, the team wanted to have the minimum possible dimensions able to reduce the costs for building the chassis and limit the mass of the total robot. Max dimensions for the total robot was to be within a volume of 29.5 in (height) by 29.5 in (width) by 59 in (length). The dimensions of the chassis were determined to be 17.5 in (height) by 19.5 in (width) by 50 in (length). These dimensions were determined based on the estimated size for the width of the wheels, needed height for the trencher, and the height needed for the bucket. 

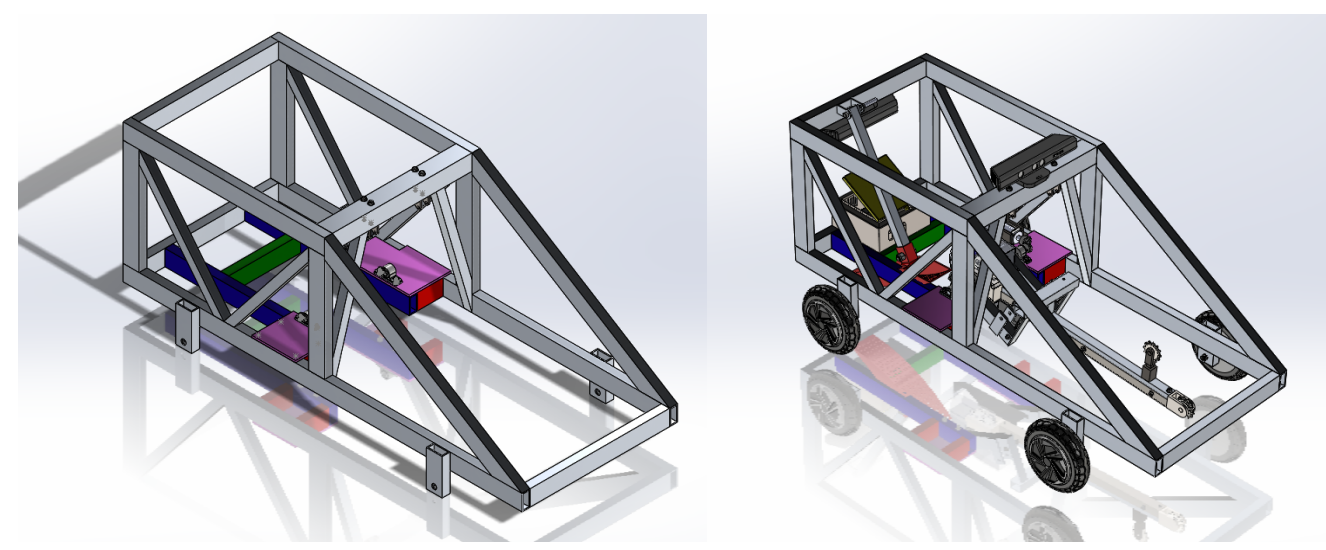

Figure 3: The above pictures are the conceptual final designs for the chassis (Left) and the full robot assembly (Right)

\section{Drivetrain}

The sub-team decided that wheels were the best solution to power the robot drive system because treads made steering difficult in last year's robot. To determine the right motor for the wheels, the surface area of the wheels to the ground had to be calculated using a MATLAB program with different wheel diameters to see how low the robot would sink.

Once the wheel diameter was chosen from the MATLAB program, the sub-team was able to pick out a wheel and motor. With the diameter of 8 inches, a motor needed to be selected utilizing the radius of the wheel and the traction of the ground so a maximum amount of torque could be produced. The torque needed to drive the robot with the trencher in the ground at the highest angle of depression (60 degrees) was $25.43 \mathrm{lb}$-ft with a factor of safety of 1.5. Members were able to research what motor provided the amount of torque needed. After online research and much consideration, multiple wheels and motors were considered and put into a design matrix shown below.

\begin{tabular}{|c|c|c|c|c|c|c|c|}
\hline & $\begin{array}{c}\text { Durability } \\
(15 \%)\end{array}$ & $\begin{array}{c}\text { Traction } \\
(20 \%)\end{array}$ & $\begin{array}{c}\text { Motor } \\
\text { Power } \\
(20 \%)\end{array}$ & $\begin{array}{c}\text { Cost } \\
(15 \%)\end{array}$ & $\begin{array}{c}\text { Weight } \\
(15 \%)\end{array}$ & $\begin{array}{c}\text { Assembly } \\
(15 \%)\end{array}$ & Total \\
\hline $\begin{array}{c}\text { Beach Cart } \\
\text { Wheels }\end{array}$ & 6 & 7 & 6 & 4 & 7 & 2 & 5.45 \\
\hline
\end{tabular}




\begin{tabular}{|c|c|c|c|c|c|c|c|}
\hline $\begin{array}{c}\text { Power } \\
\text { Wheels }\end{array}$ & 9 & 7 & 7 & 9 & 7 & 3 & 7 \\
\hline $\begin{array}{c}\text { Hoverboar } \\
\text { d Wheels }\end{array}$ & 8 & 6 & 9 & 9 & 5 & 9 & 7.65 \\
\hline
\end{tabular}

Scale: 1 (Poor) - 10 (Excellent)

Figure 4: Design matrix for wheels

From the design matrix, hoverboard wheels were the sub-system's best solution to driving the robot. The hoverboard wheels did not specify the torque it can handle, so the torque had to be calculated from the maximum weight capacity $(220 \mathrm{lbs})$ and the radius of the wheel. The torque for the hoverboard wheels ended up being $36.7 \mathrm{ft}-\mathrm{lbs}$ per wheel. Once the calculations proved that the hoverboard wheels were durable to pull the robot, custom controllers had to be purchased for the Controls sub-team.

The hoverboard motor and wheel combination saved a significant amount of work in configuring a motor package with a hall effect sensor built in, but there were several complications. The largest complication in this case was the size of the wheel. The hoverboard wheels the sub-team utilized were 8 inches in diameter and 1.25 inches wide. The width of the hoverboard wheel was simply too small to prevent the robot from sinking into the BP-1. To increase the support provided by the wheel, the surface area needed to be increased. This was done by designing a wheel cover to bolt over the hoverboard wheel. With the rubberized surface of the wheel, mounting was determined to be a straightforward process of bolting two half wheels together. The expanded wheels increased the size of the wheels to approximately 3.5 inches wide with an 8.4 inches diameter. This size increase was determined using our wheel sink calculations. The tread design is similar to that of a skid-steer loader and was designed to be $3 \mathrm{~d}$ printed.
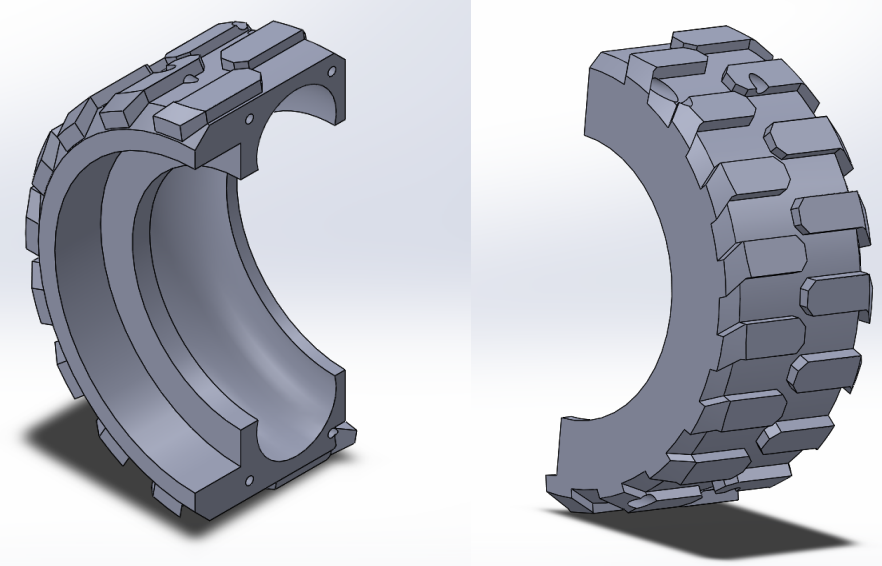

Figure 5: Hoverboard wheel cover 


\section{Wheel Sink Calculations}

With the importance of ride height for the trencher, it was imperative that the team was aware of how much the robot would sink in the BP-1. Additionally, it was important that our robot would not sink and would be able to function fully on the BP-1. To determine how deep the robot would sink, several calculations had to be done. The simplest was determining the amount of surface area in contact with the BP-1 at any given time. This calculation in conjunction with the weight of the robot and the paper Soil Test Apparatus for Lunar Surfaces (Rahmatian and Metzger) detailing the supportive properties of BP-1 at various depths allowed us to create a MATLAB program to calculate how far the wheels would sink depending on their diameter and width. Knowing how far the robot was going to sink the mounting position of the wheels was then determined so that the trencher was at the optimal height.

\section{Skid Steering}

Skid steering was decided upon for simplicity in the mechanical design of the robot. The simplicity also made the software easy to design around for the Controls sub-team. The team was able to avoid having to design a more complicated steering and suspension system. In addition to simplicity, this was decided on to help reduce weight by eliminating several additional materials as well as motors or a dedicated steering system. A rack and pinion steering system would have increased the weight of the front and reduced the room needed for the trencher. With the limited time and the limited weight capacity of the robot, the desire to have a rack and pinion steering would have to be researched for a different competition year where more time and weight reduction can apply to this year's prototype.

\section{Material Handling}

The Material Handling sub-team worked with three main mechanisms that would dig, transport, and dump gravel through the following: trencher, ramp, and bucket. The sub-team designed many concept ideas, and the ideas narrowed down to these systems. As the team progressed into prioritizing on these mechanisms, modifications were conducted from SolidWorks (3D modeling program) and ANSYS (finite element analysis program) in the design stage. This was done to improve the collection performance, transportation of material, shielding from dust, and the use of lightweight materials. Once the designs were combined with the Chassis and Drivetrain subsystem and all components were checked over, the sub-system was ready to be built and welded.

\section{Digging}

From the results of the last few years' performance, the team chose a trencher system because it was the best theoretical idea that could clear regolith and retrieve gravel with the revised rules. The trencher design was chosen based on a design matrix with an emphasis on the goals of the competition through a distribution of ranking and point status. The main purpose for the team's designs, analysis, and simulations was to determine the trencher's ability to collect gravel 
through a motor gearbox, test the durability of the trencher boom's strength, and examine the trencher's linear actuator force to drive the boom into the ground.

\section{Trencher Boom}

The trencher boom was the main component of the trencher and holds the the gearmounts, chain, tensioning system, and sprockets. In the development of the trencher, aluminum tubing was decided on due to its light weight and durability from the thickness of the hollow tube. The hollow tube would have a thin steel plate underneath to protect from shear and provide extra strength for the tubing. Bolts connected the steel gearmounts to the aluminum tubing because they could not be welded together with the experience the sub-team had in welding.

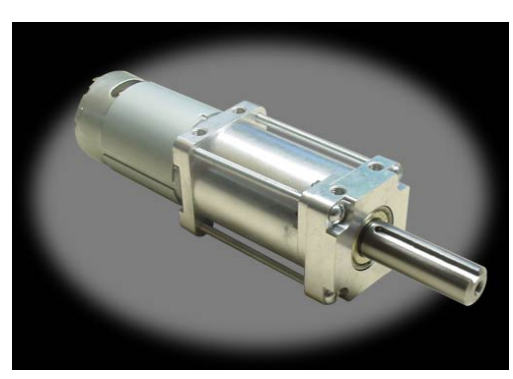

\section{Trencher Motor}

A DC motor and a gearbox was the best option to supply enough torque for the trencher. Once that option was chosen, calculations were needed to determine the right motor and gearbox for the trencher. The trencher was examined to determine how much torque was needed and the desired RPM was decided from the sub-team. The sub-team ended up using a RS-550 DC motor and a 256:1 P60 gearbox from Banebots.

Figure 6: Trencher motor/gearbox

The sub-team discovered that the current and torque were linear to RPM when plotted out, and the sub-team found what current and torque was drawn from different RPMs. 

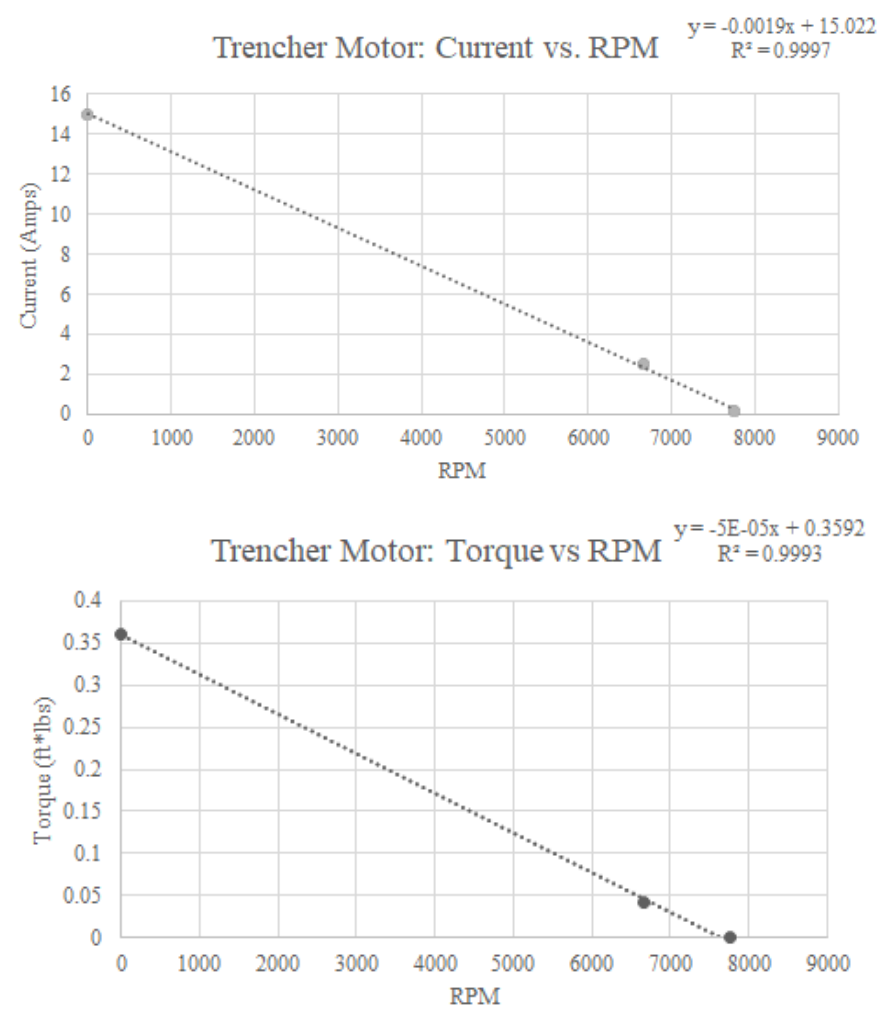

Figure 7: Linear relationship with current and torque from RPM

\section{Chain}

The chain of the trencher was a size 40 roller chain that possessed the same pitch as the sprockets that the team had. The roller chain was researched and was capable of undergoing the forces applied from the trencher. The 40 chain was rated at $350 \mathrm{lbs}$ and the forces that the trencher boom endured were $240 \mathrm{lbs}$ at most (with 4 teeth into the ground). The zinc-coated steel screws that connected the teeth to the chain were determined to verify that they would not shear. The pressure on the cross-section of the screw was calculated using the force on the teeth divided by the cross-sectional area of the screw. The pressure was 101.5 psi when the yield strength of screws were 33,000 psi. The usage of finite element analysis (FEA) could have applied but with time constraints, the calculations could give a quicker definite answer to determine if any bending would occur.

\section{Teeth}

Two versions of the teeth were created for the displacement of the sand and gravel. These teeth underwent many iterations to determine the most sand pushed and the most amount of gravel that was picked up. FEA was conducted on each iteration for the teeth designed. Different versions of the sand teeth were developed and compared using FEA. The complexity of these two teeth can be seen in Figure 8. 


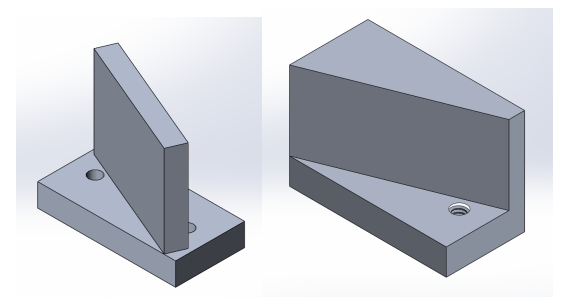

Figure 8: Different iterations of the trencher teeth

With the two designs, the less complicated one on the right (Figure 9) was chosen and utilized for the robot. FEA testing with ANSYS was examined to determine the total deformation of the teeth. This FEA looked at the equivalent stress of the teeth. The von Mises force was used to because it demonstrates when the material will be ductile and where. The total deformation as shown below gave the best visual on where the teeth will suffer the most impact when colliding with the teeth.

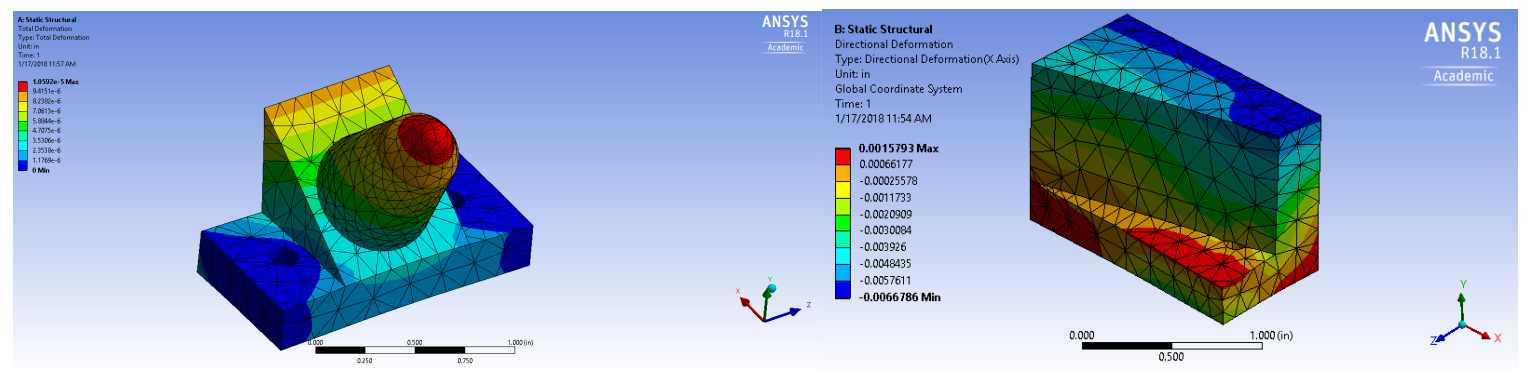

Figure 9: FEA of the chosen trencher teeth

\section{Chain Tensioning}

A spring tensioning system was included with the trencher to tighten up the chain. This was considered and inserted onto the robot because of unwanted buckling. The chain needed to be tight so that the chain did not fall off or become loose otherwise it could fail. Other suspension systems included the boom suspension system that was built to protect the actuators and boom from damage when the boom made contact with the surface. The spring forces were researched and the total amount of force needed to keep the boom suspended.

\section{Trencher Actuators}

The linear actuators that support the trencher's depth and position had the power to support over $400 \mathrm{lbs}$ total (200 lbs per actuators). The actuators had to have enough force to prevent the robot from lifting itself, so the actuators had to supply more force than the robot. The calculations were done to keep the trencher 3 inches above the ground with a 6 inch stroke length. The same actuators were tested last year because they were still operable from competition and utilized them again. 


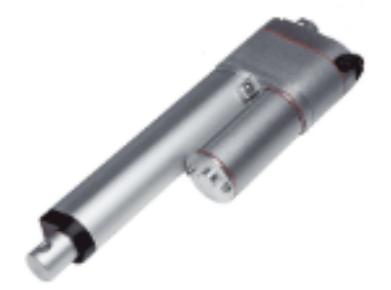

Figure 10: Linear actuator used

\section{Gearmounts}

The trencher's place of impact other than the teeth were the gearmounts where the pivot point of the sprockets would impact the connection to the trencher mainframe. The gearmounts had to be examined closely to support the force of the gravel when the trencher passed the regolith. The gearmounts were designed to house the sprockets that the sub-team had and were custom-made to support the sprocket. The connection to the trencher boom had to be bolted onto the trencher boom because forces that the trencher would undergo could not support the welding connection with aluminum and steel.

After the gearmounts were designed to house the sprockets and their rods, FEA was conducted on the structure of the gearmount with the known forces that applied. The FEA tested the axle joints where the sprockets are located and determined if aluminium was usable.
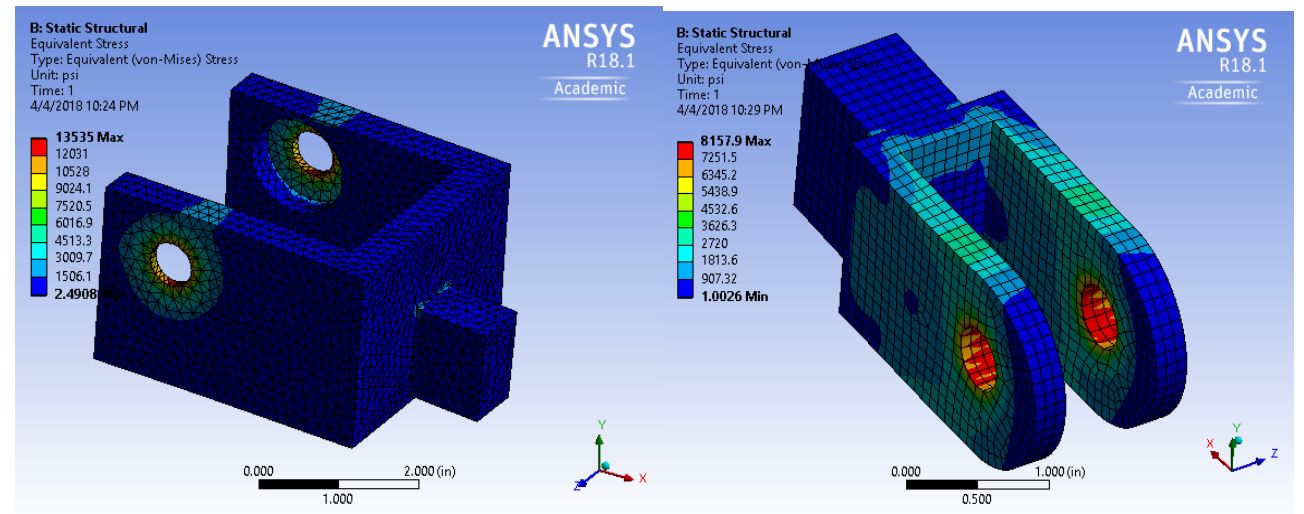

Figure 11: FEA with gearmounts for the trencher

Aluminum 6061's yield strength is 8,000 psi, and both analyses tested above the pressure (McMaster-Carr). Steel was chosen to ensure that the gearmounts were not ductile during the mining of the gravel.

\section{Shielding and Protection}

To prevent debris and dust from entering the circuitry and the other mechanics of the sub-system, shielding was considered as a priority to the trencher. The requirement from the NASA Systems Engineering Handbook was to have dust protection against the moving components with the 
trencher (NASA SE Handbook). Since the other priority was weight conservation, the covers needed to have the lightest weight possible with the most protection available. The shielding for both covers was going to be composed of PLA plastic due to 3D printing. A late revision noted that the bottom shield supporting the collection ramp could shatter the plastic. In that critical case, the bottom shield was determined to need to be made with thin sheet metal to support the ramp as well as the weight and speed of the gravel during runtime.

\section{Transportation of Material}

Accompanied with the decision to use the trencher system to dig up regolith, the design team made a ramp that would be capable of pulling gravel up into a collection area. This was decided because it would be an idea that did not require any additional motors and could use the motor torque created by the trencher to move gravel forward and upward. It was a simple design that would decrease the amount of moving parts present in the whole system.

The idea began as a motorized ramp much like a bucket system used on robots made for the previous year's competition. The motor drives the brushes which in turn carry the gravel into an area where the ramp would be mobile and could carry gravel at will of the motor it is being run by. This idea was shut down somewhat quickly, as there were many moving parts involved and it became complicated to work out where the power was going to come from. This problem led the sub-team to consider the trencher power that was already being taken as the source to gather the gravel upwards into our collection bin.

Using spare gravel, and the natural angle of depression, the sub-team was able to calculate the height that the bucket had to be in order to get the amount of material that is needed for each collection, which would have to be the height of the ramp above the ground. Then, using trigonometry, the team was able to determine the length the ramp would need to be using a 60degree angle of depression for the trencher and calculated so the ramp would just reach the regolith when the robot was collecting. This determined the length of the ramp that was manufactured, and the amount of allowed depression from the robot itself.

After the final design was considered, the ramp was manufactured using a $1 / 8$ inch steel plating. It was cut, and meticulously bended to fit the design at hand. This part was going to be used to test out different variations in materials. A second ramp is to be made out of aluminum plating, and one more steel one will potentially be made to see how the material handles the amount of stress put onto it by the trencher and the gravel. This ramp was also going to be attached to the shield that was designed to go around the trencher, so that the ramp would have the most amount of support possible to keep it in place. If these other ramps are manufactured in time, then the ramps will be attached with screws and lock-washers. If not, these two will be attached via metal rivets similar, to those used in airplane. 


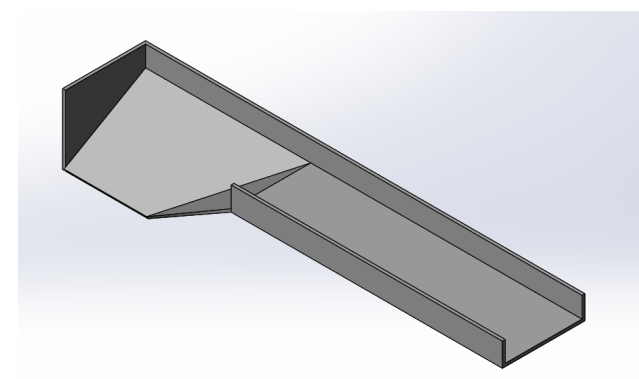

Figure 12: The design of the ramp

\section{Dumping}

In order to transport the collected gravel from the robot to the collection bin, the team decided to use a pivoting bucket system. The bucket would be positioned under the ramp to collect the gravel. Originally the bucket was to be manufactured using aluminum, however after analyzing the size constraints of where the bucket can be located, the team determined it was better to $3 \mathrm{D}$ print the bucket, allowing for more creativity within the design and a lighter design.

Small holes were added to the bottom of the bucket to allow extra regolith to pass through but not allow any 1 inch diameter pieces of gravel to be lost since scoring is based on the amount of gravel collected and not regolith. The curved shape of the bucket was designed to be concentric with the pivot point so that the path the bucket travels is known in order to ensure it does not hit the trencher mechanism. The bucket was attached to an aluminum tube that was attached to the top support beam of the chassis to ensure that the bucket would dump the gravel outside of the chassis and into the collection bin. To attach the dump arm to the shaft of the motor, a mount was designed to be screwed to the side of the dump arm, and then have the motor shaft go through the dump arm and the mount. The mount would be secured to the motor shaft via set screws.

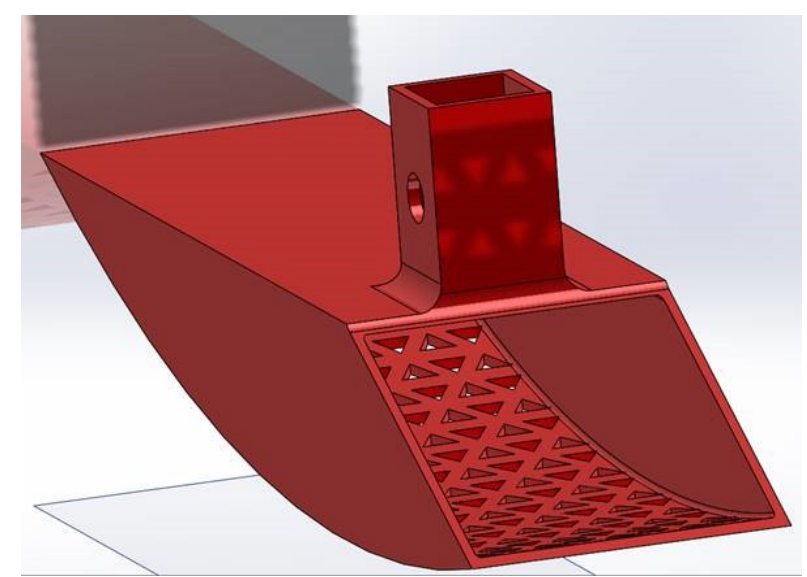

Figure 13: The design of the dumping bucket arm. 


\section{Controls}

The Controls sub-team worked on two different modules dedicated to powering the robot and ensuring motor control and allowing the drivers to communicate with the robot.

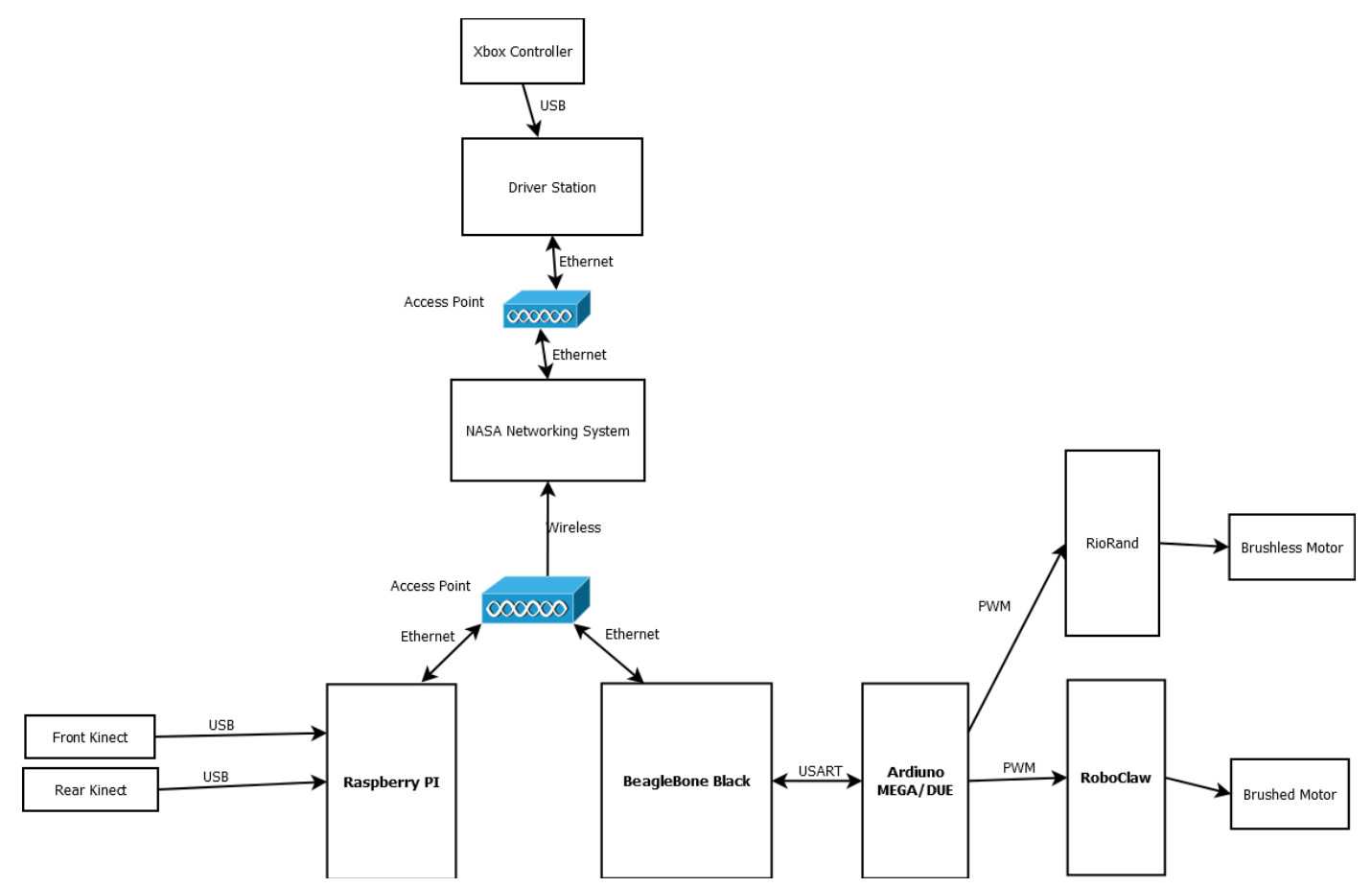

Figure 14: A visual model of the control system

\section{Power Distribution and Motor Control}

Motor control was handled using an Arduino Mega and multiple motor controllers. Because the robot used brushless motors for the chassis sub-system and brushed motors for the material handling subsystem, multiple types of motor controllers were needed. For the brushed controllers, 2 RoboClaw 2x60A, 6-34VDC Regenerative Motor Controllers were used. For the brushless controllers, 4 RioRand 30A Brushless Motor Speed Controllers were used. The RoboClaw controllers were chosen because the team already possessed several, thus saving money. The RioRands were chosen because they were the least expensive controllers capable of powering the motors. Originally, brushed motors were to be used for all motors. This was changed due to power consumption concerns. The current system has the Arduino receiving commands from the networking module which are interpreted into signals sent to the motor controllers. Power is provided by several $28 \mathrm{~V}$ Milwaukee Tools Batteries.

\section{Networking and Driver Control}

Driver control of the robot was accomplished by using network protocols such as TCP and UDP to send commands from a driver station to the robot. The driver station is a laptop running a JavaFX application which displays camera feeds, connection status, and other information to the drivers (Figure 2). The design for the driver station was inspired by the design of the driver 
station used in FIRST Robotics Competitions, as many members of the team were familiar with that layout and design.

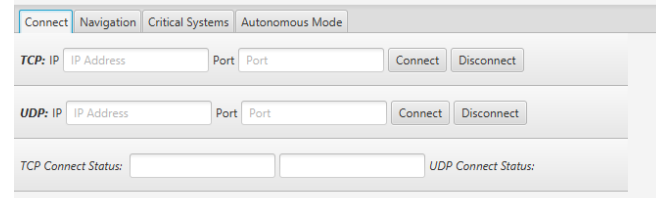

Figure 15: The driver station with no robot connection

The driver station also sent commands to the robot over TCP (Figure 15). The commands were instructions to be carried out by the robot. They were sent over as string variables. The commands were sent over the provided network infrastructure via two routers, one on the robot and one with the drivers. This system was decided on due to the ease with which it could be programmed and debugged.

Commands sent to the robot were received either by a Raspberry Pi which acted as a camera server or a Beaglebone Black which forwarded the commands to the Arduino. The Pi received camera feeds from the two Xbox 360 Kinect devices, one mounted on the front of the robot and the other on the back. These devices were chosen because of their ability to provide depth mapping, which will be useful when automation is added to the system in the future. The Beaglebone was used primarily due to early design decisions involving the use of low-level IR sensors which would have been controlled by the Beaglebone. Those sensors were cut from the project due to time constraints. In the future, the Beaglebone will be removed and the roles of it and the Pi will be consolidated. 


\section{Final Design \& Fabrication}

\section{Final Design}

The robot's final design was composed on SolidWorks and used ANSYS to verify that the robot was structurally compatible for trenching. The team used SolidWorks because it was a useful, universal way to share the final design with every team member with the assistance of the application "Box." With the sharing of files, the design of the robot was always being verified by other members and sub-systems. Each member of the team acted as a systems engineer to ensure that their component would fit with other designs. The final design on SolidWorks gave a 3D visual representation of the robot and illustrated the general mechanics of the robot. Those mechanics included how the wheels would operate, how the trencher would push into the dirt via actuators, where the gravel from the trencher would land, and how the dumping arm would rotate and release the gravel collected. These designs were studied with finite element analysis with the known forces to components like the trencher teeth, chassis, rods, and gearmounts.

\section{Fabrication}

The fabrication process began after the final assembly was created. Drawings for the robot specified all the dimensions, hole locations, threads, and tolerances that needed to be communicated to other team members that did not design a certain part. Clear methods in communicating proper specifications were highly amplified to save time and confusion. Fabrication also included an organized way of requesting parts from budgeting. A list of parts was generated from the final assembly for all sub-systems and received approval by budgeting in a timely manner to have enough time for manufacturing the raw material and assembly. When raw material was delivered, the team began cutting, milling, bending, drilling and welding the aluminum and steel. PLA plastic was used with the top shielding and was deburred and attached on to the steel gearmounts. The bottom ramp was turned into a flat sheet that the team was able to cut out, so that it could support the ramp that would be attached to it. The ramp was also turned into a flat piece, was cut, and then bent into shape. This portion was difficult to perform, as pieces had to be bent in multiple different directions.

\section{Phase D: Experimentation}

After the final design stage was complete, testing began on the robot's vital mechanisms that contribute to the main function of the robot. This process was the key to functionality.

\section{Drilling}

Due to the time constraints, testing the trencher was very limited. The force on the teeth was tested in the gravel to determine how much physical damage the teeth would possess. The chain tensioning system was able to tighten the chain and prevent buckling. The sprockets and chain were tested in sand (substitute for BP-1) to determine if clogs would form. With no lubrication to 
the chain, clogs and jams were less likely to be present. The trencher motor was tested with power sources with the gearbox and was successfully able to transfer enough torque needed to drive the trencher and drill through the gravel.

\section{Dumping}

The dumping arm motor was previously tested to verify that the arm can support at least $20 \mathrm{lbs}$. The motor came from a used Chevy Impala's chair, so the sub-team wanted to make sure the motor was in working order. The seat motor was deemed successful in lifting the weight. The next experiment was attaching the arm with the bucket attached to determine if it could swing the arm and bucket. That experiment was successful in rotating the mechanism. The last step was adding gravel to the bucket to have the motor drop off the collection. With the added weight, the motion was identical.

\section{Wheels}

The wheels were hooked up to the controller and to a power source to verify that the wheels could drive. The wheels drove and were connected to the frame of the robot. With the mounting system secured with the wheels, the torque of the robot was able to push the frame of the robot.

\section{Budgets}

\begin{tabular}{|c|c|c|c|}
\hline Sub Team & Budgeted & Expended & Budget Remaining \\
\hline Chassis & $\$ 1800.00$ & $\$ 797.17$ & $\$ 1002.83$ \\
\hline Controls & $\$ 1000.00$ & $\$ 213.18$ & $\$ 786.82$ \\
\hline $\begin{array}{l}\text { Materials } \\
\text { Handling }\end{array}$ & $\$ 1200.00$ & $\$ 538.40$ & $\$ 661.6$ \\
\hline
\end{tabular}

Figure 16: Robot sub-team budget for 2017-2018

A goal for this project was to try to make the robot cost effective as it was a completely new team and finding additional funding was anticipated to be, and proved to be, very difficult. The budgets designated in the above table were established after completing our design matrices and evaluating the anticipated costs of materials. There was approximately $20 \%$ added to each budget beyond the amount requested by each individual team to account for fluctuations in prices and unexpected expenditures. 
The materials handling and chassis teams were able to come in far under budget as they were able to get items cheaper than had been originally expected. In some cases this was due to investing more time into looking at multiple vendors for better pricing and in other cases adjustments from the initial plan which resulted in lower cost.

The cost saving methods of the materials handling and chassis sub-teams were also used by the controls team. The more significant impact was their ability to scavenge lightly used parts from other projects that had originally been planned as being purchased.

\begin{tabular}{|c|c|c|c|}
\hline & Budgeted & Expended & Budget Remaining \\
\hline Outreach & $\$ 500.00$ & $\$ 283.06$ & $\$ 216.94$ \\
\hline Travel Reserve & $\$ 1000.00$ & $\$ 0.00$ & $\$ 1000.00$ \\
\hline
\end{tabular}

Figure 17: Outreach and travel budget

Beyond the cost of the robot we also budgeted for other expenses the team was expected to incur throughout the year. Though there is only one outreach event required, we set aside a rather large budget. This was done with the intent of hosting multiple outreach events to help share the STEM enthusiasm with children.

The budget for the travel reserve is still wholly intact as the team is working with several local companies in an attempt to get low, or entirely covered, freight cost to ship the robot to the competition. If there is capital remaining after shipping the robot, the travel reserve money will be applied to the cost of lodging and travel for the team members lessening the money that is being spent out of pocket. Most of travel to Florida is out of pocket for the students.

\section{Risk and Reliability}

With any system, it's vital to consider our own personal safety and the safety of the project as a whole. As per the rules given to us by NASA, the team installed a red emergency-stop button which will be clearly visible and easily accessible. This ensured that in the case of malfunction, the robot could forcibly shut down, preserving both the safety of the robot and anyone in its proximity. The team examined the robot and recognized that from the NASA competition that "human capabilities and limitations must enter into designs." This means that the users, the designers, and the mechanics of the robot must be able to withstand any error possible. This allowed the test runs to be completely safe for all observers and people working on the project. 


\section{Project Management}

\section{Team Structure}

The team focused on using good communication techniques and teamworking skills in order to get the robot functioning. The primary team communication method was emails, where the

officers and team leads would send out all meeting notes and reminders for team events. On top of that, the team used the Telegram app for additional reminders and quick to answer questions. Sub-team leads and officers also used WhenIsGood to help coordinate schedules. To ensure team-working skills, a president, vice president, secretary, and treasurer were elected from the whole team. The president and vice president were in charge of making the constitution, being in charge of registration, planning team events, and contacting sponsors. The treasurer was in charge of keeping the budget updated, and the secretary was in charge of taking notes, booking rooms, and sending out meeting reminders.

The sub-teams chose leaders from among themselves to be in charge of representing the subteam, giving progress reports at team meetings, and to ensure that the sub-team stays focused during the sub-team meeting. Documentation was stored on Google Drive and sub-team leaders were in charge of creating meeting minutes for other members' absences. With Google Drive, sub-team leaders were in charge of keeping documents, spreadsheets, and presentations organized for any member to find. Other files like CAD files, drawings, code files, and other supportive files were stored using Box. Sub-team leaders were in charge of properly storing files neatly with the same principle as Google Drive. Since Box was not an ideal location to store and edit code at the same time, a GitHub account was created for the Controls sub-team and subteam leaders were in charge of managing the code.

\section{Schedule of Work}

Project planning was managed by a Gantt chart that plotted out the course of this year's schedule. The Gantt chart discussed the deadlines for completing the robot, planned meetings, testing, and dates for competition. Due to this year's team starting their first robot, there were many modifications that happened and late parts caused setbacks. The Gantt chart was still updated and was a tool to manage the planning time. The modified Gantt chart is shown in Appendix A.

\section{Conclusion}

By using an engineering process, teamwork, and dedication, the Milwaukee School of Engineering's NASA Robotic Mining Competition team was successfully able to build their robot. Their mining robot will compete at the Kennedy Space Center in May. 


\section{Acknowledgments}

- Dr. Farrow, our advisor

- Helped us through the entire project, including the team structure and competition process

- Ditch Witch

- Helped us with calculations that were beyond our abilities 


\section{References}

“Aluminum 6063-T5,” MatWeb. Web. Available:

http://www.matweb.com/search/datasheet.aspx?matguid=79875d1b30c94af39029470988004fb6.

[Accessed: 08-Apr-2018]

“Aluminum 6063-O,” MatWeb. Web. Available:

http://www.matweb.com/search/datasheet.aspx?matguid=bcd1 abbd8d6d47b1b9896af80a3759c6

\&ckck=1. [Accessed: 08-Apr-2018]

L. A. Rahmatian and P. T. Metzger, "Soil Test Apparatus for Lunar Surfaces," Earth and Space 2010: Engineering, Science, Construction, and Operations In Challenging Environments, 2010.

NASA. NASA RMC SE. NASA - Eligibility, Rules, and Resources. NASA.

Web. Available:

https://nen.nasa.gov/documents/14218/2007703/Expanded+Guidance+for+NASA+SE++Vol+1.pdf/8df9c2b4-f898-427d-a217-388ab4aa88df. [Accessed: 08-Apr-2018].

"McMaster-Carr," McMaster-Carr Roller Chain, 2014. Available:

https://www.mcmaster.com/\#6261k173/=1c9uo7q. [Accessed: 08-Apr-2018]. 


\section{Appendix A}

\begin{tabular}{|c|c|c|c|c|c|}
\hline Task & Task Name & Duration & Start & Finish & Predecessors \\
\hline & Design Robot & 146 days & $9 / 18 / 2017$ & $4 / 8 / 2018$ & \\
\hline & Build Robot & 51 days & $2 / 6 / 2018$ & $4 / 17 / 2018$ & \\
\hline 1 & Form Team & 13 days & Thu 9/7/17 & Mon 9/25/17 & \\
\hline 2 & Design Goals & 1 day & Tue 9/26/17 & Tue 9/26/17 & 1 \\
\hline \multirow[t]{3}{*}{3} & $\begin{array}{c}\text { Functionality } \\
\text { of Robot }\end{array}$ & 18 days & Mon 9/18/17 & Mon 10/4/17 & 2 \\
\hline & $\begin{array}{c}\text { Preliminary } \\
\text { Designs }\end{array}$ & & & & \\
\hline & Control & 122 days & $\begin{array}{c}\text { Mon } \\
10 / 30 / 17\end{array}$ & Tue $4 / 17 / 2018$ & \\
\hline 4 & $\begin{array}{l}\text { program } \\
\text { the arduino }\end{array}$ & 122 days & $\begin{array}{c}\text { Mon } \\
10 / 30 / 17\end{array}$ & Tue $4 / 17 / 2018$ & $2,10,12,13,14$ \\
\hline 5 & $\begin{array}{r}\text { program a } \\
\text { user interface }\end{array}$ & 122 days & $\begin{array}{c}\text { Mon } \\
10 / 30 / 17\end{array}$ & Tue $4 / 17 / 2018$ & $2,10,12,13,14$ \\
\hline 6 & $\begin{array}{l}\text { program a } \\
\text { tcp server }\end{array}$ & 21 days & $\begin{array}{c}\text { Mon } \\
10 / 30 / 17\end{array}$ & Mon 11/27/17 & 2 \\
\hline 7 & $\begin{array}{c}\text { program a } \\
\text { serial } \\
\text { communicatio } \\
\text { n }\end{array}$ & 27 days & $\begin{array}{c}\text { Mon } \\
10 / 30 / 17\end{array}$ & Tue $12 / 5 / 2017$ & 2 \\
\hline
\end{tabular}




\begin{tabular}{|c|c|c|c|c|c|}
\hline 8 & $\begin{array}{l}\text { Create a } \\
\text { control } \\
\text { systems } \\
\text { outline }\end{array}$ & 5 days & $\begin{array}{c}\text { Mon } \\
10 / 30 / 17\end{array}$ & Fri 11/3/17 & $2,10,12,13,14$ \\
\hline \multirow[t]{2}{*}{9} & $\begin{array}{l}\text { preliminary } \\
\text { designs }\end{array}$ & 30 days & $\begin{array}{c}\text { Mon } \\
10 / 30 / 17\end{array}$ & Fri 12/8/17 & 2 \\
\hline & Drive Train & 39 days & $\begin{array}{c}\text { Wed } \\
10 / 18 / 17\end{array}$ & Sat $12 / 9 / 17$ & \\
\hline 10 & Wheel Design & 39 days & $\begin{array}{c}\text { Wed } \\
10 / 18 / 17\end{array}$ & Sat $12 / 9 / 17$ & 2 \\
\hline \multirow[t]{2}{*}{11} & $\begin{array}{l}\text { Chassis } \\
\text { Design }\end{array}$ & 24 days & Wed 11/8/17 & Sat $12 / 9 / 17$ & $2,10,12,13,14$ \\
\hline & $\begin{array}{l}\text { Material } \\
\text { Handling }\end{array}$ & 31 days & $\begin{array}{c}\text { Mon } \\
10 / 30 / 17\end{array}$ & Sat $12 / 9 / 17$ & \\
\hline 12 & $\begin{array}{c}\text { Trencher/Chai } \\
n\end{array}$ & 31 days & $\begin{array}{c}\text { Mon } \\
10 / 30 / 17\end{array}$ & Sat $12 / 9 / 17$ & 2 \\
\hline 13 & $\begin{array}{l}\text { Ramp w/ } \\
\text { Screen filter }\end{array}$ & 31 days & $\begin{array}{c}\text { Mon } \\
10 / 30 / 17\end{array}$ & Sat $12 / 9 / 17$ & 12 \\
\hline \multirow[t]{2}{*}{14} & $\begin{array}{l}\text { Holding } \\
\text { chamber }\end{array}$ & 31 days & $\begin{array}{c}\text { Mon } \\
10 / 30 / 17\end{array}$ & Sat $12 / 9 / 17$ & 12 \\
\hline & $\begin{array}{l}\text { Power } \\
\text { System }\end{array}$ & & & & \\
\hline 15 & $\begin{array}{c}\text { Design } \\
\text { Control Box }\end{array}$ & 15 days & $3 / 20 / 2018$ & $4 / 8 / 2018$ & $4,7,8$ \\
\hline
\end{tabular}




\begin{tabular}{|c|c|c|c|c|c|}
\hline 16 & $\begin{array}{l}\text { Electrical } \\
\text { Layout }\end{array}$ & 87 days & $12 / 9 / 2017$ & $4 / 8 / 2018$ & $\begin{array}{c}2,10,12,13,14,1 \\
5\end{array}$ \\
\hline 17 & Mock-Up & 2 days & Sat 12/9/17 & Mon 12/11/17 & $10,12,13,14$ \\
\hline 18 & $\begin{array}{l}\text { Design } \\
\text { Review }\end{array}$ & 7 days & $\begin{array}{c}\text { Mon } \\
12 / 11 / 17\end{array}$ & Tue 12/19/17 & 17 \\
\hline 19 & $\begin{array}{l}\text { Update } \\
\text { Design }\end{array}$ & 76 days & $12 / 19 / 2017$ & Fri 4/6/2018 & 18 \\
\hline 20 & Final review & 2 days & Sat $4 / 7 / 2018$ & Sun $4 / 8 / 18$ & 19 \\
\hline 21 & Order Parts & 75 days & Tue $12 / 26 / 17$ & Mon 4/8/2018 & 20 \\
\hline 22 & Fabrication & 51 days & Tue $2 / 6 / 18$ & Tue $4 / 17 / 18$ & 19 \\
\hline 23 & $\begin{array}{c}\text { Systems } \\
\text { Paper }\end{array}$ & 61 days & Tue $1 / 16 / 18$ & Tue $4 / 10 / 18$ & 18 \\
\hline 24 & $\begin{array}{l}\text { Robot } \\
\text { Testing }\end{array}$ & 5 days & Wed 4/18/18 & Tue $4 / 24 / 18$ & 22 \\
\hline 25 & $\begin{array}{c}\text { Practice } \\
\text { Operations }\end{array}$ & 5 days & Wed $4 / 18 / 18$ & Tue $4 / 24 / 18$ & 22 \\
\hline 26 & Proof of Life & 5 days & Wed 4/18/18 & Tue $4 / 24 / 18$ & 24 \\
\hline 27 & Box and Ship & 4 days & Wed $4 / 25 / 18$ & Mon 4/30/18 & 26 \\
\hline
\end{tabular}

Figure 18: Gantt chart for 2017-2018 school year 


\section{Appendix B}

\begin{tabular}{|c|c|c|}
\hline Command & Description & Expected Return Value \\
\hline $\begin{array}{l}\text { FWD }\{\text { speed } \\
\{\text { duration }\}\end{array}$ & $\begin{array}{l}\text { Moves the robot forwards at a given speed } \\
\text { for a duration of time }\end{array}$ & none \\
\hline $\begin{array}{l}\mathrm{BWD}\{\text { speed } \\
\text { duration }\end{array}$ & $\begin{array}{l}\text { Moves the robot backwards at a given speed } \\
\text { for a duration of time }\end{array}$ & none \\
\hline LFT $\{$ speed $\}$ duration $\}$ & $\begin{array}{l}\text { Turns the robot in place and to the left at a } \\
\text { given speed for a duration of time }\end{array}$ & none \\
\hline RIT \{speed $\{$ duration $\}$ & $\begin{array}{l}\text { Turns the robot in place and to the right at a } \\
\text { given speed for a duration of time }\end{array}$ & none \\
\hline $\begin{array}{l}\text { M1 }\{+/ \text {-speed }\} \\
\{\text { duration }\}\end{array}$ & $\begin{array}{l}\text { Moves the first motor at a given speed for a } \\
\text { duration of time }\end{array}$ & none \\
\hline $\begin{array}{l}\text { M2 }\{+/ \text {-speed }\} \\
\{\text { duration }\}\end{array}$ & $\begin{array}{l}\text { Moves the second motor at a given speed } \\
\text { for a duration of time }\end{array}$ & none \\
\hline $\begin{array}{l}\text { M3 }\{+/ \text {-speed }\} \\
\{\text { duration }\}\end{array}$ & $\begin{array}{l}\text { Moves the third motor at a given speed for a } \\
\text { duration of time }\end{array}$ & none \\
\hline $\begin{array}{l}\text { M4 }\{+/ \text {-speed }\} \\
\{\text { duration }\}\end{array}$ & $\begin{array}{l}\text { Moves the fourth motor at a given speed for } \\
\text { a duration of time }\end{array}$ & none \\
\hline $\begin{array}{l}\text { MT }\{+/ \text {-speed }\} \\
\{\text { duration }\}\end{array}$ & $\begin{array}{l}\text { Moves the trencher at a given speed for a } \\
\text { duration of time }\end{array}$ & none \\
\hline $\begin{array}{l}\text { rot }\{+/ \text {-speed }\} \\
\{\text { duration }\}\end{array}$ & $\begin{array}{l}\text { Rotates the robot in place at a given speed } \\
\text { for a duration of time }\end{array}$ & none \\
\hline STOP & $\begin{array}{l}\text { Stops all robot motion and prevents future } \\
\text { motion until sent again }\end{array}$ & none \\
\hline hello & $\begin{array}{l}\text { Used by the heartbeat protocol to test } \\
\text { connection }\end{array}$ & hi \\
\hline fcam & $\begin{array}{l}\text { Ensures that the front camera is the one } \\
\text { currently broadcasting. }\end{array}$ & none \\
\hline rcam & $\begin{array}{l}\text { Ensures that the rear camera is the one } \\
\text { currently broadcasting. }\end{array}$ & none \\
\hline
\end{tabular}

Figure 19: A table of the command codes 